\title{
EMPODERAMENTO FEMININO EM BELÉM: ANÁLISE DAS NARRATIVAS PUBLICADAS NO PERFIL DO INSTAGRAM @GIRLPOWERBELEM
}

\author{
Ana Paula de Mesquita AZEVEDO ${ }^{I}$ \\ Marilia JARDIM ${ }^{2}$ \\ Alda Cristina Silva da COSTA ${ }^{3}$
}

\begin{abstract}
RESUMO
A vida social é marcada pelos diferentes tempos e movimentos culturais que presentes na sociedade, sendo um desses movimentos o feminismo que busca a igualdade entre homens e mulheres. Simmel discute, a partir da Sociologia Compreensiva que o todo deve ser tratado como sujeito da sociedade, sendo que esse grupo pode ser constituído por mulheres em busca de direitos iguais. No universo feminino, é possível perceber que se busca combater a legitimação de poder de uma sociedade machista e patriarcal, evidenciada pelos chamados meios de comunicação de massa. Entretanto, com a facilidade das novas tecnologias tem oportunizado espaço para o empoderamento feminino, principalmente em redes sociais online, como no perfil Grl Pwr Belém, na rede social online Instagram. O objetivo deste artigo é apresentar a força feminina em exposição no perfil @GrlPwrBelém (http://instagram.com/grlpwrbelem) por meio dos depoimentos publicados que apresentam relatos e opiniões sobre o feminismo. Foram escolhidos três depoimentos diferentes publicados no perfil e foi feita a análise narrativa dos textos. As redes sociais online têm dado voz e representação que os meios de comunicação de massa não oferecem, pois obedecem a um padrão e formam estereótipos dos demais. Os depoimentos compartilhados mostram a singularidade das pessoas a partir da aceitação do próprio corpo, sendo que é possível que outras pessoas se identifiquem com essas histórias. $\mathrm{O}$ presente trabalho buscou apresentar novas formas de empoderamento feminino exposto nas redes sociais online, como forma de ativismo político e reação contra os padrões impostos pelos meios de comunicação de massa.
\end{abstract}

Palavras-chave: Movimento Feminista. Midiatização. Narrativas.

\begin{abstract}
Social life is marked by the different times and cultural movements that are present in society, one of these movements being feminism that seeks equality between men and women. Simmel discusses, from Comprehensive Sociology, that the whole must be treated as a subject of society, and that group can be constituted by women in search of equal rights. In the feminine universe, it is possible to perceive that one seeks to combat the legitimation of power of a macho and patriarchal society, evidenced by the so-called mass media. However, with the ease of the new technologies, women's empowerment has been given space, especially in online social networks, such as the Grl Pwr Belém profile, in the online social network Instagram. The aim of this article is to present the feminine force on display in the @GrlPwrBelem profile (http://instagram.com/grlpwrbelem) through the published testimonies that present reports and opinions on feminism. Three different testimonies published in the profile were chosen and the narrative analysis of the texts was done. Online social networks have given voice and representation that the mass media do not offer because they obey one standard and form stereotypes of the others. The shared testimonies show the uniqueness of the people from the acceptance of the body itself, and it is possible that other people identify with these stories. The present work sought to present new forms of female empowerment exposed in online social networks 1 Mestranda do Programa de 2 Mestranda do Programa de pela Universidade Federal do Pós-Graduação em Comuni- Pós-Graduação em Comuni- Pará (UFPA), Pós-Doutora pelo cação, Cultura e Amazônia cação, Cultura e Amazônia (UFPA) sob a orientação da (UFPA) sob a orientação Profa. Dra. Alda Cristina Cos- da Profa. Dra. Alda Cristita - anapazmesquita@gmail. na Costa - jardimmarilia@ com. gmail.com. Programa de Comunicação, Linguagens e Cultura na Universidade da Amazônia (PPGCL/UNAMA). Professora do Programa de Pós-graduação Comunicação, Cultura e Amazônia (PPGCom/ UFPA).
\end{abstract}

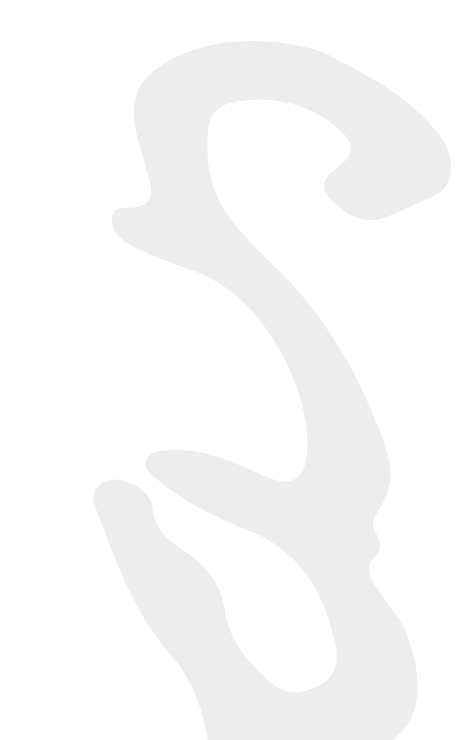

3 Doutora em Ciências Sociais

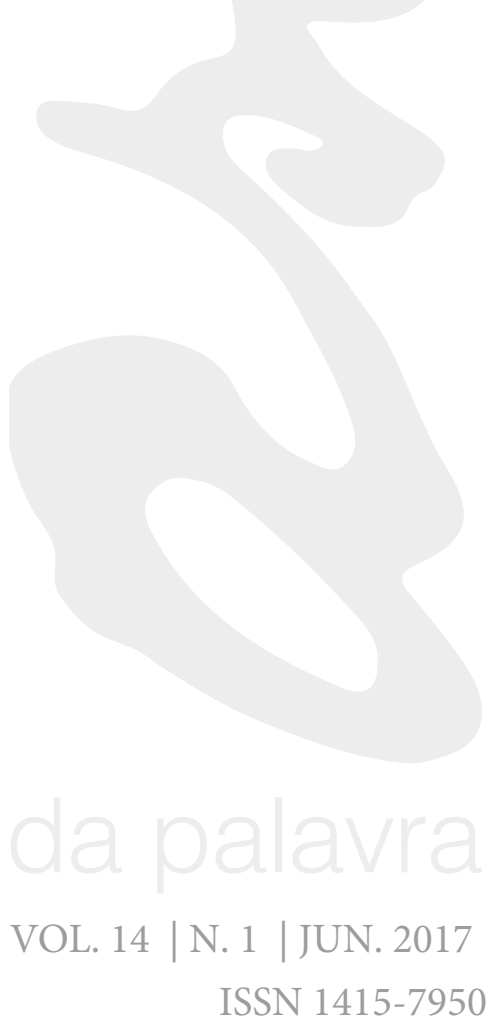


as a form of political activism and reaction against the standards imposed by the mass media.

Keywords: Feminist Movement. Midiatization. Narratives.

\section{INTRODUÇ̃̃O}

A vida social é marcada pelos diferentes tempos e movimentos culturais que presentes na sociedade, sendo um desses movimentos o feminismo que busca a igualdade entre homens e mulheres. Simmel (2006) discute, a partir da Sociologia Compreensiva, e aponta que o todo deve ser tratado como sujeito da sociedade, sendo que esse grupo pode ser constituído por mulheres em busca de direitos iguais. No universo feminino, é possível perceber que se busca combater a legitimação de poder de uma sociedade machista e patriarcal, evidenciada pelos chamados meios de comunicação de massa. Entretanto, com a facilidade das novas tecnologias tem oportunizado espaço para o empoderamento feminino, principalmente em redes sociais online, como no perfil Grl Pwr Belém, na rede social online Instagram.

O objetivo é apresentar neste trabalho a força feminina em exposição no perfil Girl Power Belém (http://instagram.com/grlpwrbelem) por meio dos depoimentos publicados que apresentam relatos e opiniões sobre o feminismo e foi feita a análise narrativa das imagens e textos a partir de Motta que aponta a narrativa como uma maneira de "Compreender um pouco mais o ser humano na sua complexidade, entender o mundo humano, demarcar nossas identidades, o que somos, como nos constituímos é o trabalho simbólico das análises das narrativas" (MOTTA, 2013, p.30).

Véron (2014) aponta para a midiatização como um processo que vai além dos aparatos técnicos de comunicação: o campo das instituições, a mídia e os atores sociais são afetados pela midiatização, assim, os meios de comunicação de massa, principalmente, trabalham com a repetição de padrões e falta de representatividade na sua programação. As redes sociais online têm dado voz e representação que os meios de comunicação de massa não oferecem, pois obedecem a um padrão e formam estereótipos dos demais. Os depoimentos compartilhados no perfil mostram a singularidade das pessoas a partir da aceitação do próprio corpo, do tipo de cabelo e da orientação sexual, sendo que é possível que outras pessoas se identifiquem com essas histórias.

\section{A MULHER E O MOVIMENTO FEMINISTA}

É histórico o desafio da mulher para adquirir seu lugar de destaque na sociedade. Enfrentou preconceitos, violências de todas as formas e sempre foi centro de reflexões em vários campos da sociedade. Assim como todo e qualquer movimento social, a necessidade e insatisfação das pessoas em relação as instituições, costumes, etc. é que gera a ação dos indivíduos. As mulheres que por um longo tempo sofreram preconceitos e o desrespeitos caladas, resolveram bradar e lutar pelos seus direitos. Muitas dessas mulheres que sofriam violência domésticas, discriminação de seus companheiros, chefes, colegas de trabalho e não tinham coragem de manifestar sua dor e indignação.

Simone de Beauvoir (1970) aponta que a mulher sempre apareceu de forma negativa e limitada. Sempre coube a essa mulher a imagem da fragilidade e de um ser que precisaria de complemento. Isto é, como se o homem fosse o sujeito absoluto e a mulher precisaria desse complemento do homem absoluto. "A humanidade é masculina e o homem define a mulher não em si, mas relativamente a êle; ela não é considerada um ser autônomo" (BEAUVOIR, 1970, p. 10). Ainda reforçando essa a ideia de que a mulher para a maioria dos sujeitos não seria um ser absoluto, Beauvoir (1970, p. 10) destaca a fala do crítico, filósofo e novelista Julien Benda na obra "Rapport d'Uriel” que diz o seguinte: “(...) O Homem é pensável sem a mulher. Ela não, sem o homem". 
Sobre esse reforço da mulher ser inferior ao homem, surgiu a indagação de como essa situação chegou a se estabelecer dessa forma entre os indivíduos. Simone de Beauvoir questionou-se como a mulher deixou-se se tornar submissas e sem contestação? A filósofa, feminista e intelectual percebeu que essa submissão ocorreu pela falta de reciprocidade, solidariedade e reconhecimento que foram construídos durante muito tempo. E para explicar essa falta de unicidade entre as mulheres, Beauvoir (1970) faz reflexões sobre o movimento dos operários e negros onde eles se fortaleceram socialmente em virtude da união, da força dos grupos.

Os proletariados dizem nós. Os negros também. [...]. As mulheres - salvo em certos congressos que permanecem manifestações abstratas - não dizem nós. [...]. Os proletariados fizeram a revolução da Russia e os negros do Haiti. [...] A ação das mulheres nunca passou de uma agitação simbólica; só ganharam o que os homens concordaram em lhes conceder; elas nada tomaram; elas receberam. Isso porque não tem os meios concretos em de se reunir em uma em uma unidade que se afirmaria em se opondo. Não tem passado, não tem história, nem religião própria; não tem como os proletariados, uma solidariedade de trabalhos e interesses; não há se quer entre elas uma promiscuidade espacial que faz dos negros dos E.U.A, dos judeus dos guetos, dos operários de Saint-Denis ou das fábricas da Renault uma comunidade. Vivem dispersas entre os homens, ligadas pelo habitat, pelo trabalho, pelos interesses econômicos, pela condição social a certos homens - pai ou marido - mais estreitamente do que as outras mulheres (BEAUVOIR, 1970, p. 13).

Neste trecho Beauvoir reforça a ideia de que não existe uma unicidade, solidariedade entre as mulheres. Não existia, naquela época, força para que elas se firmem socialmente. Aqui a intelectual levanta a questão sobre a importância da sororidade e da força em grupo. Da importância de união dos indivíduos em busca da sua luta e direitos. A sororidade, neste sentido, torna-se uma das características importante para que o movimento feminista se firme e legitime na sociedade. Manter essa relação de união fortalece o grupo. É o caminho para adquirir o respeito que a mulher perdeu durante o tempo. É a oportunidade da mulher, como Beauvoir (1970) destaca, de se reconhecer como sujeito e não como outro, sair dessa condição de mulher vassala para assumir um papel de destaque e força social.

\section{OS MOVIMENTOS SOCIAIS NA INTERNET}

Para Castells (2013), os movimentos socais se originam de uma crise cotidiana que se torna insuportável para a maioria das pessoas. Pessoas essas que desconfiam das instituições que administram a sociedade e que por conta da falta das ações dessas instituições, geram nos indivíduos a revolta e insatisfações. "Os movimentos sociais muitas vezes são desencadeados por emoções derivadas de algum evento significativo que ajuda os manifestantes a superar o medo e desafiar os poderes constituídos [...]" (CASTELLS, 2013, p. 127). O primeiro passo motivador a ser dado pelos individuo na luta pelos seus direitos, são as emoções. A ação individual ou coletiva é motivada pela emoção, assim como, segundo Castells (2013) qualquer reação do ser humano é motivada pela emoção. Dessa forma, entendemos que as ações das mulheres feministas são provocadas pela emoção presentes na indignação, medo, insatisfação ou na raiva de serem discriminadas ou desrespeitadas.

E Castells (2013) afirma que o primeiro gatilho da ação coletiva é a raiva que aumenta a medida que a injustiça é descoberta. Já o medo, ainda segundo o autor, desencadeia a ansiedade e a evitação do perigo. E esse medo só é superado 
quando compartilhado com outro em um processo de ação comunicativa. Quando o indivíduo divide com alguém seu medo. E depois que esse indivíduo divide esse sentimento, o medo é superado e transforma em entusiasmo.

Quando se desencadeia o processo de ação comunicativa que induz a ação e a mudança coletiva, prevalece a mais poderosa emoção positiva: o entusiasmo, que reforça a mobilização societária intencional. Indivíduos entusiasmado, conectados em rede, tendo superado o medo, transformam-se num ator coletivo consciente. Assim, a mudança social resulta da ação comunicativa que envolve a conexão entre redes de redes neurais dos cérebros humanos estimuladas por sinais de um ambiente comunicacional formado por redes de comunicação. A tecnologia e a morfologia dessas redes de comunicação dão forma ao processo de mobilização e, assim, de mudança social, ao mesmo tempo como processo e como resultado (CASTELLS, 2013, p. 128).

Com a tecnologia esse processo comunicacional se torna mais ativo. Promovem as interações entre os indivíduos promovendo as trocas de informações e o fomento da ação coletiva. Para a realização ou ação dos movimentos sociais, esse processo comunicacional e a tecnologia, induzem e estimulam muito mais as mobilizações coletivas. Essas mobilizações são provocadas por que o processo comunicacional pela tecnologia possibilita um grande alcance e rapidez nas informações. A interação entre os indivíduos é imediata. Não há limites de tempo e nem espaço.

Com a internet, os movimentos sociais não precisam de um controle ou um líder formal para comandar o grupo para passar informações ou instruções. E essa forma de em que se caracteriza os movimentos sociais atuais possibilitam uma ação coletiva participante. Onde todos os membros do grupo se envolva no movimento. Castells (2013, p. 129) diz que esse novo cenário em que se encontra os movimentos sociais atuais reduz a vulnerabilidade dos movimentos na internet. Pois é um espaço que sempre está em mudança e fluxo intenso, em constante interação e sempre agregando participantes. E promovo um espaço de autonomia para os movimentos sociais.

Os movimentos são simultaneamente locais e globais. Começam em contextos especificos, por motivos próprios, constituem suas próprias redes e constroem seu espaço público ao ocupar seu espaço urbanos e se conectar as redes de internet. Mas também são globais, pois estão conectados com o mundo inteiro (CASTELLS, 2013, p. 130).

Os movimentos sociais na internet se conectam com outras redes, outros movimentos, pessoas que fomentam o debate e convoca a participação pública. E possibilita conhecer outras vivencias, experiências que podem servir de estímulos para a própria mobilização. Essa relação entre movimentos sociais e internet, é muito rico e importante para gerar nos indivíduos a inquietação conhecimento da sua realidade. É estar a par do que acontece na comunidade e no mundo. Além de permitir estreitar relações com outros indivíduos que se identificam com a mesma causa.

Ainda que os movimentos sociais atuais atuem no cenário da tecnologia, da internet, é preciso o senso de coletividade. De solidariedade. De união. De pertencimento. Refletir que uma mobilização se faz pelo coletivo. E que o indivíduo sozinho não tem tanto força como estando em grupo.

\section{A IMPORTÂNCIADO GRUPO PARA O MOVIMENTO SOCIAL FEMI-} NISTA 
mungam o mesmo pensamento e interesses. O movimento feminista é uma representação da luta das mulheres por respeitos e direitos. Nesse sentido, o mais importante para que essas mulheres que se encontram insatisfeitas e indignadas com suas condições enquanto mulheres na sociedade e, que lutam pelo destaque e visibilidade de sua luta e ideal, é a união entre elas. Simmel (2006), sociólogo alemão, diz que o indivíduo sozinho, não é tão forte enquanto em grupo.

Assim, compreende-se que para a legitimidade de um grupo e/ou movimento feminista em sociabilidade é preciso compreender as necessidades dos indivíduos e sobre esse indivíduo em sociedade. Para Simmel (2006) esse indivíduo em sociedade "é pressionado por todos os lados, por sentimentos, impulsos e pensamentos contraditórios, e de modo algum ele saberia decidir com segurança interna suas diversas possibilidades de comportamento" (SIMMEL, 2006, p. 40). O indivíduo em grupo se fortalece e passa a ter decisões mais firmes em busca de suas necessidades. Ele sozinho hesita seus impulsos, quando encontra o outro com as mesmas intenções, ele deixa de hesitar. Assim o que se compreende é que o indivíduo busca unir-se ao outro para a conquista de uma força que não é física, e sim, social. "O asseguramento da existência, [...] o desejo de afirmar e expandir a própria esfera de poder, [...] - este são impulsos fundamentais para os indivíduos, impulsos a partir do quais ele pode se associar de modo conveniente a muitos outros indivíduos" (SIMMEL, 2006, p. 41). O que Simmel quer dizer é que o desejo do poder e de ser firmar socialmente é uma vontade de cada indivíduo, é o que ele chama de impulso primitivo, e que, portanto, ao se associar com o outro as buscas desses impulsos tornam-se conveniente. Esse movimento pode ser percebido nos movimentos feministas, pois existe a necessidade de afirmação ou legitimação para se fazer ver e ouvir. Isso se torna mais notório e evidente quando esse indivíduo está em grupo.

Quando um indivíduo tem a pretensão de ser notado diante do outro, sozinho ele pode conseguir essa expressividade, porém em grupo, essa força é muito mais intensa e necessária para atender as necessidades desse sujeito. Simmel (2006, p. 52) diz que o indivíduo em grupo se torna tão forte que é capaz de comover e envolver por um sentimento tão forte as massas. Compreendendo essa lógica de pensamento do sociólogo, quando a massa está totalmente imbuída pelo sentimento, não há como negar o poder desse indivíduo em grupo. E a ação desse grupo, passa a ser mais firme e consistentes no tecido social. Esse encantamento e emotividade das massas mostra como os grupos se firmam na sociedade e como esse indivíduo atua diante ou inserido nessa massa. Dessa forma, sentimentos são aflorados, o que faz parte das estratégias de quem pretende agir sobre as massas, assim como a própria massa para arrastar consegue os indivíduos.

Por esse motivo, qualquer pessoa que tenha pretendido agir sobre as massas sempre consegui fazer isso apelando para o sentimento [...] Aqui há algo que se poderia chamar de nervosismo coletivo: uma sensibilidade, uma paixão, uma excentricidade frequentemente próprias das grandes massas, raramente demonstrada em qualquer um de seus integrantes considerado isoladamente (SIMMEL, 2006, p. 52).

A emotividade das massas elas acontecem em conjunto. Esse sentimento, sensibilidade se realizam em coletividade. O indivíduo se envolve por essa carga de emoção. Talvez ele nem sinta isso sozinho. Aqui é o poder da massa que é possível observar em muitos grupos, movimentos sociais e que também pode envolver o indivíduo sem que ele tenha qualquer resistência. "Esse fenômeno se deve provavelmente à influência mútua, ocorrida por intermédio das emanações de sentimentos difíceis de se detectar" (SIMMEL, 2006, p. 52). Não é só indivíduo que é arrebatado, ele pode vir a assumir a posição de arrebatador desses sentimentos que pode ser direcionado a um sentimento que Simmel diz (2006, p. 54) eticamente valioso, pois coloca o sujeito para além do valor individual.

Notamos que essa força do indivíduo em grupo defendida por Simmel VOL. $14 \mid$ N.1 $\mid$ JUN. 2017 
(2006) pode dialogar com o conceito de reciprocidade de Beauvoir (1970), onde ela aborda a união de forças das mulheres. O que identificamos na atualidade como sororidade. A união em grupos, principalmente nas redes sociais online nos dias de hoje, permite maior demonstração de força já que o compartilhamento de informações se tornou muito mais dinâmico. Essa nova forma de trocar informações levou os estudos na área de Comunicação às novas perspectivas, como a compreensão da midiatização.

\section{MIDIATIZAÇÃO E A SOCIEDADE ORGANIZADA A PARTIR DAS EX- PECTATIVAS DA MÍDIA}

Estudos na área da Comunicação já promovem novas perspectivas de compreensão do processo a partir das condições econômicas, culturais e sociais dos indivíduos e não mais considera o ato de se comunicar como troca de informação. $\mathrm{O}$ processo de "midiatização" é um dos novos caminhos da área da Comunicação em que o entendimento segue em processo e, por isso, existem diferentes compreensões entre os autores. $\mathrm{O}$ fenômeno da midiatização é diferente, por esta razão considera os contextos sociais e culturais.

Pesquisadores da área de Comunicação sistematizam a midiatização como processo em que a sociedade começa a organizar suas práticas sociais, políticas e afetivas de acordo com as expectativas da mídia. Na segunda metade do século XX, esse processo tomou fôlego e às mídias foi dado o papel estratégico de mediação. Temos hoje um panorama social no qual nossas experiências são cada vez mais permeadas por relações comunicacionais que, em determinado momento, são perpassadas pela mídia, promovendo assim novas formas de interação social: as esferas da vida social e individual se reorganizam em função da lógica midiática (SCHIMTZ, 2007, p. 2).

Sobre o tema, Antonio Fausto Neto aponta uma sociedade midiatizada de natureza social fragmentada e em constante construção:

nestes termos, a sociedade na qual se engendra e se desenvolve a midiatização é constituída por uma nova natureza sócio-organizacional na medida em que passamos de estágios de linearidades para aqueles de descontinuidades, onde noções de comunicação, associadas a tota - lidades homogêneas, dão lugar às noções de fragmentos e às noções de heterogeneidades. (FAUSTO NETO, 2006, p. 3)

Em síntese, Sgorla explica que:

$\mathrm{Na}$ "sociedade midiatizada", a cultura do campo midiático e dos demais campos sociais se bifurcam mediante a expansão das tecnologias midiáticas, o que se dá segundo múltiplas, infinitas, descontínua, heterogêneas e complexas formas, intensa e extensamente, objetiva e subjetivamente, formal ou informalmente, na sistemática do tecido social. Com efeito, os atores sociais acabam reconfigurando seu modo de estar no mundo e são condicionados a uma nova experiência; a uma nova forma de existência social; a novos vínculos; a novos modos de agir, acolher significados e produzir sentidos; a novas estruturas para perceber e pensar o real; a novos mecanismos de tomadas de decisão; e a novos meios de interagir e de comunicar que só têm validade na jurisdição da "sociedade midiatizada". (SGORLA, 2009, p. 67). 
dos meios e das mediações e concebe três campos que instituem relações e são influenciados por elas: das instituições, das mídias e dos atores sociais. As práticas sociais atuais são afetadas de diferentes maneiras pelos processos de midiatização.

$\mathrm{O}$ autor defende que a sociedade mediatizada surge quando os meios se constituem com instituições e deixam de ter como fim o serviço de comunicação, já que eles passam a ser produtores de sentido, seguindo a lógica de um modelo já estabelecido. A midiatização é o nome dos fenômenos midiáticos que foram institucionalizados dentro da sociedade. Verón (2014) aponta para uma perspectiva antropológica da midiatização, como o resultado da capacidade de semiose cujo resultado se expressa na produção de fenômenos midiáticos:

A midiatização certamente não é um processo universal que caracteriza todas as sociedades humanas, do passado e do presente, mas é, mesmo assim, um resultado operacional de uma dimensão nuclear de nossa espécie biológica, mais precisamente, sua capacidade de semiose. Essa capacidade foi progressivamente ativada, por diversas razões, em uma variedade de contextos históricos e tem, portanto, tomado diferentes formas (VERÓN, 2014, p. 14).

Se considerada apenas os adventos técnicos, a midiatização pode ser datada a partir de uma nova invenção, assim sendo para as ocorrências históricas que se institucionalizam na sociedade. Três observações são apontadas por Véron (2014) em relação ao processo não linear da midiatização: 1) o crescimento dos meios produz efeitos radiais, ou seja, o alcance dos efeitos se esvai por todas as direções, com intensidades diferentes; 2) não há linearidade nos processos dos fenômenos midiáticos; 3) as duas observações anteriores tem como consequência a aceleração do tempo histórico.

Os fenômenos midiáticos criam independência entre emissores e receptores e como consequência há uma des-contextualização das informações, já o que tinha significado em determinado espaço e/ou tempo pode passar a ter outro significado em uma ocasião diferente: "A descontextualização abre a porta para múltiplas quebras de espaço e tempo produzidas por qualquer dispositivo técnico de uma forma específica, ao longo de toda a história da midiatização" (VÉRON, 2014, p. 17).

Há também uma diferenciação entre a comunicação direta, ou face a face, e a mediada por algum dispositivo:

No meu ponto de vista, a comunicação humana é completamente não linear, em todos os seus níveis de funcionamento, pois é um sistema auto-organizador distante do equilibrio. A especificidade do face a face da comunicação não é sua suposta linearidade, mas a ausência de fenômenos midiáticos (VERÓN, 2014, p. 17).

Para Verón (2014), a sociedade mudou com os meios de comunicação porque, através dos meios, a comunicação passou a dar ordens à social focada na vivência mediada: as pessoas pautam suas vidas, suas conversas e suas histórias a partir do que está colocado pela mídia.

Desde o fim dos anos 1990 e começo dos anos 2000, a Internet se tornou cada vez mais acessível e, consequentemente, ter alcance de informações novas e diferentes se tornou mais fácil graças ao barateamento de aparelho e serviços de conexão. Além de ler notícias vindas de diferentes cantos do mundo, as pessoas também começaram a criar e compartilhar conteúdos sobre os mais diferentes temas.

Assim, a mídia de massa, como são chamados os sistemas de imprensa, rádio e televisão, passou a disputar espaço e atenção com as redes sociais online. O compartilhamento de novos conteúdos permitiu dar voz às classes que não estão representadas em novelas, filmes, programas de TV etc. As pessoas discutem, ques- VOL. $14 \mid$ N. 1 | JUN. 2017 
tionam, publicam e dividem as suas opiniões no espaço online, como funciona o perfil@grlpwrbelem analisado nesse trabalho, já que os depoimentos pessoais são compartilhados como narrativas pessoais e talvez nunca tivessem essa oportunidade em outros meios de comunicação.

\section{NARRATIVAS: EXPERIÊNCIAS E CONHECIMENTO COMPARTILHA- DO}

Narrativas são histórias e histórias são contadas o tempo todo. Ao contar histórias, fazemos escolhas sobre o que vai ser contado e o que vai ser omitido em determinado espaço, seja físico, como o espaço de um jornal, seja abstrato, como ocorre ao contar uma história. Motta (2013) em "Análise da Narrativa Crítica", discute a narrativa a partir de uma perspectiva de enunciação, ou seja, a proposta está focada no processo de comunicação narrativa.

$\mathrm{O}$ autor aponta seis razões para estudar narrativas. Primeiro, é uma maneira de entender quem somos a partir das histórias que contamos: "Compreender [..] o ser humano na sua complexidade, entender o mundo humano, demarcar nossas identidades, o que somos, como nos constituímos é o trabalho simbólico das análises das narrativas" (MOTTA, 2013, p.30).

Segundo, ainda de acordo com Motta (2013), é uma forma de entender as representações do mundo que são criadas a partir das narrativas e que permeiam a sociedade contemporânea que se cruzam nas relações humanas. Terceiro, e ainda sobre representações, narrativas permitem esclarecer as diferenças entre representações reais e fictícias. A quarta razão pela qual devemos estudar as narrativas é elas servem para entendermos o passado recriado por meio das histórias e até onde essas histórias realmente aconteceram. Também é uma maneira de identificarmos como histórias se tornam legitimas dentro da sociedade. Por fim, estudar narrativas é necessário para que as histórias sejam melhores contadas e renovadas ao surgimento de novas técnicas que permitem a troca de informação.

Motta (2013) reflete sobre o significado da linguagem na experiência e conhecimento humano e coloca a narrativa no centro das discussões da realidade social. A linguagem permite que o mundo adquira sentido, sendo essa linguagem oral, imagética, escrita. A teoria narrativa, chamada de narratologia, é o campo de estudo e um método de análise da prática de contar histórias: "A narratologia procura entender como sujeitos sociais constroem os seus significados através da compreensão e expressão narrativa da realidade, inclusive através das mídias" (MOTA, 2008, p. 144).

As mídias, atualmente, também são as redes sociais online que permitem o armazenamento de uma memória social e de narrativas a partir das suas imagens como é o caso dos perfis de Instagram. As lembranças e histórias daquelas imagens estão compartilhadas em rede e se tornam referências de uma realidade que é narrada por meio das fotos e textos publicados:

Como referência de acontecimentos, as imagens do mundo contemporâneo que recebemos diariamente em nossas casas via satélite ou internet, são consideradas evidencias ou documentos da realidade narrativa. Embora icônicas e, portanto, representações à semelhança do real, muitas dessas imagens nos chegam por um processo de visualização ou de mediatização, que está sujeito a regras de controle e que vão além dos processos produtivos de filmagem ou captação de cenas (MOTA, 2012, p. 200).

Embora Motta (2008) discuta a narratologia a partir do campo jornalístico, as etapas de recomposição da intriga, de identificação de conflitos, construção de personagem, estratégias comunicativas, relação comunicativa e significado das me- 
tanarrativas serão utilizadas para a compreensão do perfil @girlpowerpowerbelem analisado nesse estudo.

\section{O FEMINISMO PRESENTE NAS NARRATIVAS DO PERFIL GIRL POWER BELÉM}

A@GirlPowerBelem é um perfil no Instagram que aborda vários relatos de mulheres a respeito do feminismo, empoderamento e sororidade, sobre os preconceitos que enfrentam para se firmar enquanto mulher na sociedade. É um grupo de mulheres que se encontram para uma conversa sobre feminismo em um espaço em que elas são percebidas e escutadas por muitos.

Foi possível perceber no perfil a reciprocidade, a solidariedade entre elas. Dois conceitos que dialogam com Beauvoir (1970) quando diz que a mulher precisaria se unir para se legitimar em sociedade. Assim como Simmel (2006) quando também fala da sociação e a força do grupo nas relações sociais.

O uso da rede social demonstra a midiatização dos discursos que antes eram menos conhecidos, afinal, o perfil @grlpwrbelem permite dar voz às diferentes opiniões sobre o movimento feminista, sem julgamentos, compactuando e incentivando o sentimento de sororidade e empatia.

Em entrevista realizada via correio eletrônico com a pessoa que gerencia o perfil, descobrimos uma mulher, que não quis se identificar, que conta ter problemas de depressão, mas que após buscar ajuda profissional melhorou sua saúde mental e começou a se interessar por temas como o feminismo. Assim, buscou uma maneira de ajudar e ser ajudada por narrativas empoderadoras de outras pessoas, por isso criou o perfil @girlpowerbelem.

Ela também explica que a seleção é feita de forma aleatória, sem critérios pré-estabelecidos, pois a ideia é compartilhar o maior número de histórias. Os temas também são livres, mas estão permeados por discussões sobre feminismo, empoderamento, sororidade, aceitação do próprio corpo, padrões de beleza e relatos de vivências, mas todos com a característica de narrativas pessoais.

Para compreender melhor, foram selecionados três postagens da primeira semana de maio de 2017 com depoimentos publicados no perfil para serem analisados a partir de um viés narrativo, pois são recortes de histórias.

O primeiro texto é de autoria de Rafaela Costa:

Nunca alisei meu cabelo, mas sempre tive muita vontade, a vontade passou e fui para "ditadura do cacho perfeito", achava que podia usar meu cabelo natural, mas só se não tivesse muito volume, os cachos fossem bem definidos e sem frizz. E me dei conta que não precisava ser assim, que o volume e o frizz do meu cabelo eram a característica dele, nada que eu devesse conter ou 'dar um jeito'. Então, depois de perceber que meu cabelo era bonito exatamente do jeitinho que ele era, comecei a me sentir bem melhor comigo mesma, mas tinha um porém, eu achava que o cabelo crespo e cacheado não podia ser alisado jamais. Mas entendi que a nossa aparência, cabe apenas a nós mesmas decidirmos como queremos! O feminismo me ajudou muito com relação a auto estima, eu sempre tive muitos problemas, confesso que ainda tenho alguns, mas aos poucos tô conseguindo me amar, me achar bonita como eu sou. O feminismo também me ensinou a sororidade, a importância do empoderamento pra todas nós, e me ajudou muito a me tornar a mulher que eu sou hoje. Eu estava feliz, ainda bem!

O segundo depoimento é de Larissa Correia: 
Hoje em dia você está sujeita a todo tipo de situação. Eu sempre fui magra, baixa, não por ter algum problema, mas porque meu biotipo é esse. Desde sempre ouvi comentários que me constrangiam, que muitas vezes me faziam chorar no banheiro da escola, da faculdade e eu ficava mal até no trabalho. Comecei a ler sobre aceitação do corpo e descobri que era isso que eu precisava, que isso me faria bem e que, quem tinha que aceitar o corpo magrinho, de saboneteiras aparentes era somente EU. Certa vez em um post de uma rede social, uma moça (que se diz feminista) disse a exata frase para mim: "você precisa engordar $2 \mathrm{~kg}$ pra falar comigo". Por quê eu preciso? EU ME AMO ASSIM. E me surgiu o seguinte questionamento: como algumas mulheres pregam o feminismo na mesma proporção que diminuem e denigrem as suas companheiras de luta? Mas esse questionamento é outra história... Precisamos respeitar as vivências de cada uma para juntas sermos mais! Empoderem-se meninas!

O terceiro e último post é da estudante Brenda Ferreira:

Eu estou admitindo sem medo nenhum TODOS os meus preconceitos. Por motivos maiores tenho/tinha preconceito com o feminismo. Antes de me julgar explico: Sofri repreensão de algumas mulheres que se dizem feministas e foi sério, Porém tenho amigas lindas que estão me ajudando a mudar minha visão. Não me considero feminista mas sei que o feminismo é preciso! A pouco tempo eu sofri assédio em uma rede social que me deixou totalmente abalada. Minha amiga Vitoria falou 'olha o feminismo que tu não vai com a cara ajuda a combater esse tipo de coisa'. É dificil querer ser uma pessoa melhor, é dificil mudar algo e assumir, mas estou disposta a mudar. Eu trampo rap rodeada por homens, e é dificil como mulher se impor, sempre condicionado mais com homens e acabei tendo uma visão muito machista sobre algumas coisas, mais aos poucos to sendo desconstruida pq tenho pessoas maravilhosas pra me ajudar.

No primeiro momento, é preciso entender o contexto das histórias publicadas. Afinal, "As narrativas só existem em contexto e, para cumprir certas finalidades situacionais, sociais e culturais, podem nunca ser analisadas isoladamente, sob pena de perderem seu objeto determinante" (MOTTA, 2013, p. 120). Portanto, é preciso compreender que os textos não estão isolados no mundo, mas fazem parte de uma situação social e cultural.

Cada depoimento é um trecho de uma narrativa específica, mas todas fazem parte de um contexto maior, ou seja, o grito de empoderamento feminino que ecoa nas mídias online e que se torna pauta no cotidiano, já que faz parte do processo de midiatização.

O contexto também permite associar o cotidiano como um conflito, necessário para as narrativas: "O conflito é o núcleo em torno do qual gravita tudo o mais na narrativa. São os conflitos que abrem o espaço para as novas ações, seqüências e episódios, que prolongam e mantém a narrativa viva" (MOTTA, 2005, p. 5) Os conflitos das histórias têm em comum o preconceito que se origina da necessidade de estar encaixados em um padrão já existente, imposto principalmente pela mídia por meio de propagandas, novelas, filmes e outros produtos. As histórias contadas mostram a luta pelo fim dos estereótipos sobre o que significa ser mulher na sociedade atual e defendem o ideal de liberdade e igualdade.

Para Motta (2005, p. 7) "O reconhecimento das personagens e de sua dinâ- 
mica funcional ocorre concomitantemente com a identificação dos episódios porque as personagens são atores que realizam coisas (funções) na progressão da história". As pessoas que têm o seu texto compartilhado são protagonistas das suas histórias, porém não passam de personagens do perfil, ou seja, representam uma categoria maior de mulheres com os mesmos discursos e que se identificam umas com as outras.

Na análise pragmática da narrativa a atenção desvia-se da relação narrador-texto para a relação comunicativa narrador-narratário, para o jogo entre as intencionalidades do narrador e as interpretações e reconhecimentos da audiência. A perspectiva é outra, a atenção desloca-se do texto como unidade estática para a relação comunicativa intersubjetiva. $O$ texto torna-se apenas o nexo de uma atividade interativa entre dois interlocutores (narrador e narratário) que realizam um processo, um ato comunicativo (MOTTA, 2005, p. 12).

Os discursos das narrativas do perfil @grlpwrbelem estão sempre em primeira pessoa, como forma de dar voz para as personagens, para que elas contem a sua história, além de serem escritos no tom coloquial e com linguagem típica da internet, com palavras abreviadas como "tô" para "estou" e "pq" para "porque". O texto está repleto de intencionalidades entre os narradores e narratários, como forma de mostrar uma perspectiva pessoal sobre o tema e, assim, trazer mais veracidade e confiança para o perfil que publica as histórias.

Por fim, a metanarrativa, ou seja, o pano de fundo onde essas todas essas narrativas menores ocorrem, é o contexto da sociedade atual em que a luta pelos direitos iguais entre homens e mulheres têm sido cada vez mais enfatizada pelas redes sociais e pelos meios de comunicação de massa. O objetivo é dar voz para que as mulheres possam se conhecer, conhecer outras histórias, formar grupos, ter apoio mútuo e se fazer mais forte, usando as mídias sociais online para terem suas vozes amplificadas por meio de um movimento social do grupo.

\section{CONSIDERAÇÕES FINAIS}

A internet tem dado oportunidade de compartilhar conteúdos que não são tão debatidos em mídias massivas, discussões diferentes e diversas são fomentadas, principalmente por redes sociais online, que inclusive alimentam as pautas dos veículos de comunicação. Nesse espaço, o perfil @girlpowerbelem deu voz à diversos discursos de mulheres diferentes da cidade de Belém.

Os textos publicados são narrativas pessoais, mas que encontrou no perfil algo em comum: histórias em que o feminismo e a busca pela igualdade de direitos estão explícitos. Mesmo sem se conhecerem, as mulheres que compartilham seus depoimentos encontram empatia umas com as outras.

Também é possível encontrar o conceito de sociabilidade de Simmel: as pessoas que compartilham suas narrativas não se conhecem, mas possuem o desejo comum de tornar o feminismo e a igualdade entre homens e mulheres uma ideia cada vez mais próxima e com maior alcance de público.

\section{REFERÊNCIAS}

BEAUVOIR, Simone. O segundo sexo: fatos e mitos. $4^{\mathrm{a}}$ edição. Difusão Europeia do livro: São Paulo, 1970.

CASTELLS, Manuel. Redes de indignação e esperança: movimentos sociais na era da internet. Editora: Zahar. Rio de Janeiro, 2013. 
FAUSTO NETO, Antônio. Midiatização, prática social - prática de sentido. In: PROSUL, Encontro da Rede. Comunicação, Sociedade e Sentido. São Leopoldo: Unisinos, 09/12/2005 e 06/01/2006.

MOTA, Célia Ladeira. A narrativa semiótica da imagem. In MOTTA, Luiz Gonzaga; MOTA, Célia Ladeira. CUNHA, Maria Jandyra. Narrativas Midiáticas. Florianópolis: Insular, 2012.

MOTTA, Luiz Gonzaga. Análise crítica da narrativa. Brasília: Editora Universidade de Brasília, 2013.

MOTTA, Luiz Gonzaga. A Análise Pragmática da Narrativa Jornalística. In XXVIII Congresso Brasileiro de Ciências da Comunicação, Rio de Janeiro, RJ, setembro de 2005. Disponível em: http://www.portcom.intercom.org.br/pdfs/1057680528 42738740828590501726523142462.pdf.

SGORLA, Fabiane. Discutindo o "processo de midiatização". Mediação, Belo Horizonte, v. 9, n. 8, jan/jun de 2009. Disponível em http://www.fumec.br/revistas/mediacao/article/viewFile/285/282. Acesso em 29 mai 2016.

SIMMEL, Georg. Questões fundamentais da sociologia: indivíduo e sociedade. Tradução: Pedro Caldas. Rio de Janeiro: Jorge Zahar, 2006.

VÉRON, Eliseo. Teoria da midiatização: uma perspectiva semioantropológica e algumas de suas consequências. MATRIZes. V. 8 - No 1 jan./jun. 2014 São Paulo Brasil, p. 13-19 